\title{
Finding a solution to the problem of pain: Conceptual formulation and the development of the Pain Solutions Questionnaire (PaSol)
}

\author{
Petra De Vlieger ${ }^{\text {a,b }}$, Eva Van den Bussche ${ }^{\mathrm{c}}$, Christopher Eccleston ${ }^{\mathrm{d}}$, Geert Crombez ${ }^{\mathrm{a}, \mathrm{b}, *}$ \\ ${ }^{a}$ Faculty of Psychology and Educational Sciences, Ghent University, Belgium \\ ${ }^{\mathrm{b}}$ Research Institute for Psychology and Health, Utrecht, The Netherlands \\ ${ }^{\mathrm{c}}$ Faculty of Psychology and Educational Sciences, University of Leuven - Campus Kortrijk, Belgium \\ ${ }^{\mathrm{d}}$ Pain Management Unit, The University of Bath, UK
}

Received 24 October 2005; received in revised form 11 January 2006; accepted 6 March 2006

\begin{abstract}
We report the development of the Pain Solutions Questionnaire (PaSol), an instrument designed to measure assimilative (efforts at changing or solving pain) and accommodative (accepting that pain cannot be solved, and changing life goals) responses to the problems associated with pain. Data were collected from 476 adults suffering from chronic pain. Exploratory and confirmatory factor analyses resulted in a 14-item instrument with an adequate oblique 4-factor structure: (1) Solving Pain scale (4 items), (2) Meaningfulness of Life Despite Pain scale (5 items), (3) Acceptance of the Insolubility of Pain scale (3 items), and (4) Belief in a Solution scale ( 2 items). The validity of the PaSol was further tested by its value in explaining disability and affective distress after controlling for the effects of the demographic characteristics and pain severity. The Meaningfulness of Life Despite Pain scale was important in explaining disability and affective distress. The Solving Pain scale had a unique and independent contribution in explaining affective distress. Results are discussed in terms of how a persistence in assimilative coping, even though the pain problem is insoluble, may increase hypervigilance, catastrophizing, distress and disability.
\end{abstract}

(C) 2006 International Association for the Study of Pain. Published by Elsevier B.V. All rights reserved.

Keywords: Pain; Chronic pain; Problem solving; Questionnaire; Pain catastrophizing; Acceptance

\section{Introduction}

Psychosocial variables have been identified that help explain the heterogeneity in pain severity, distress, and associated disability of chronic pain sufferers (Keefe et al., 2004). However, much less is known about the interrelationship of these variables and their importance to adjustment over time (Linton, 2001). In an attempt to further our understanding of these interrelationships, we adopt the Brandtstädter and Renner (1990) dual process model. Developed to make sense of the paradoxical finding that life satisfaction improves from middle to late

\footnotetext{
* Corresponding author. Tel.: +32926464 61; fax: +3292646489.

E-mail address: Geert.Crombez@UGent.be (G. Crombez).
}

adulthood despite increases in physical impairment, its constructs and processes may be applicable to the problem of chronic pain (Schmitz et al., 1996). Central to this model is a dynamic and action-oriented construction of coping with adversity (Skinner et al., 2003). When goals are blocked or remain unmet, people may respond with two different modes of coping: assimilative and accommodative.

Assimilative coping involves attempts to meet the blocked or unmet goal by directing efforts at changing the situation or obstacle. In pain, for example, an inability to work because of chronic pain may be solved by seeking analgesia. Assimilative coping is often the first choice, and when actions are unsuccessful people often try again or try harder. On a process level, this mode 
is characterized by a selective focus of attention upon the problem, either by increasing the importance of the goal to be met, and/or increasing the effort needed to achieve it. However, when assimilative actions prove ineffective, a switch to accommodative coping may occur.

Accommodative coping involves a resolution of the problem by changing the goal or the importance of the goal to be met. In pain, for example, patients accept that pain cannot be cured, desist from struggling to achieve unachievable goals, and make sense of their life by reorienting themselves towards different goals (McCracken et al., 2004). This mode is thought to be associated with a less rigid style of framing problems and solutions. Which type of coping mode prevails depends upon a myriad of variables (Rothermund, in press), including the controllability of the problem and the perceived consequences of the goal being achieved, blocked or unmet.

A corollary of the dual process model relevant for the problem of chronic pain is that individuals may persist in assimilative coping even though the problem is insoluble. In line with this idea, Aldrich et al. (2000) argued that chronic pain patients often persevere in framing the solution to the problem of their pain as one of cure. Although there is preliminary evidence from people suffering chronic pain that they do not display an abnormal pattern of general problem solving attitude (De Vlieger et al., 2006), there are no data on patterns of problem formulation or problem solving when the problems are specifically related to chronic pain. In this study, we report the development of an instrument designed to measure people's attitudes to the problems associated with chronic pain and their solutions, and explore its psychometric properties.

\section{Method}

\subsection{Participants}

Participants were recruited from 'self-help' groups for chronic pain in Belgium. A total of 920 chronic pain patients were invited to complete postal questionnaires. Five hundred and one patients $(54.46 \%)$ responded, which is an acceptable response rate for mailed surveys (Hinkle et al., 1985). No data are available on non-participants. Twenty-five participants were excluded because of invalid answers, leaving a final sample of 476 chronic pain patients. The sample consisted of $28.2 \%$ men and $71.8 \%$ women, aged between 25 and 92 (mean age $=52.83$ years, $\mathrm{SD}=11.28)$. Most reported pain at multiple sites $(54 \%)$, or back pain $(29 \%)$. Sixty-four percent had a higher education (longer than the age of 18 years). Only $18 \%$ of the patients were in paid employment, and $44.2 \%$ received state supported income replacement because of chronic pain. The average duration of pain since time of onset was 185 months $(\mathrm{SD}=132$, range $12-732$ months, quartiles $91-144$ 252 months). The majority of the sample (71.1\%) was receiving treatment and almost all patients (93.7\%) were using medication at the time of questioning. Seventy-four percent had undergone at least one surgery due to their pain.

\subsection{Measures}

The Pain Solutions Questionnaire ( $\mathrm{PaSol}$ ) is the new instrument under investigation. Items were developed that were related to the tenacity of attempts to solve pain, the acceptance that pain is insoluble, and the engagement with life activities despite pain. When formulating the items, we took into account that items were related to the problem solving attitudes specifically related to pain, that items were applicable in both acute and chronic situations, and that there was no item overlap with potential outcome measures (e.g., distress, disability) and process measures (e.g., attention and pain catastrophizing). Several items were derived from the Tenacious Goal Pursuit and Flexible Goal Adjustment scale of Brandtstädter and Renner (1990) which assesses assimilative and accommodative tendencies to deal with unmet goals in general. A second source for items was the Dutch version of the Chronic Pain Acceptance Questionnaire (CPAQ; Crombez et al., 1999) which is designed to measure acceptance of pain. Third, we searched for inspiration in the Illness Cognition Questionaire (ICQ; Evers et al., 2001), which measures three generic illness cognitions that reflect different ways of reevaluating the inherently aversive character of a chronic condition: helplessness as a way of emphasizing the aversive meaning of the illness, acceptance as a way to diminish the aversive meaning, and perceived benefits as a way of adding a positive meaning to the illness.

We reformulated these items according to the above considerations. Most often items had to be adapted for relevance to acute pain. Finally, we created a new set of items grounded in the dual process model. This resulted in a set of 50 items. After initial deliberation, we reduced this set to 39 items. These items were unidirectionally formulated in a simple and clear language, contained less than 20 words, and were considered unambiguous and relevant to the constructs at stake. This set was then presented to several experts in the domain of pain. Experts were asked to provide comments on face validity, intelligibility, possible item overlap with other constructs, and relevance to the overall theoretical direction. With feedback we reduced the draft questionnaire to 23 items (see Appendix A) that capture different possible solutions to the problem of pain (e.g., 'I try everything to get rid of my pain'). Participants are instructed to describe the degree to which each statement applies to them. Each item is answered on a 7-point Likert scale, ranging from 0 ("not at all applicable") to 6 ("highly applicable").

To measure pain severity, the two-item Pain Severity subscale of the Dutch version of the Multidimensional Pain Inventory (MPI; Lousberg et al., 1999) was used ("Rate the level of your pain at the present moment" and "On average, how severe has your pain been during the last week"). The MPI has been shown to have good reliability and validity (Lousberg et al., 1999). Cronbach's $\alpha$ in this study was $\alpha=.86$.

The Dutch version of the Pain Vigilance and Awareness Questionnaire (PVAQ; McCracken, 1997; Roelofs et al., 2003) was used to assess attention to pain. The PVAQ is a 16-item measure of attention to pain that assesses awareness, 
consciousness, and vigilance to pain on a 6-point scale. The PVAQ is reliable and valid (Roelofs et al., 2003). Cronbach's $\alpha$ in this study was $\alpha=.86$.

The Dutch version of the Hospital Anxiety and Depression Scale (HADS; Spinhoven et al., 1997) is a 14-item self-report screening scale for identifying affective distress. It contains two 7-item scales: one for anxiety and one for depression, both with a scoring range of $0-21$. The HADS has been shown to have acceptable reliability and validity (Spinhoven et al., 1997). In further analyses we used the total HADS scores as an index of general affective distress (Spinhoven et al., 1997). In this study, Cronbach's $\alpha$ was $\alpha=.87$.

The Dutch version of the Pain Disability Index (PDI; Pollard, 1984) was used to measure pain-related disability. The PDI is a 7-item scale measuring the degree of disability people experience in each of seven different life domains. Ratings are made on an 11-point scale. The PDI has been shown to have good reliability and validity (Tait et al., 1990). Cronbach's $\alpha$ in this study was $\alpha=.86$.

The Dutch version of the Chronic Pain Acceptance Questionnaire (CPAQ; Viane et al., 2003; McCracken et al., 2004) was used to measure acceptance of pain. It contains two scales: one for activity engagement (pursuit of life activities regardless of pain; 11 items) and one for pain willingness (recognition that avoidance and control are often unworkable methods of adapting to chronic pain; 9 items). All 20 items of the CPAQ are rated on a 7 -point scale $(0=$ never true $-6=$ always true). The CPAQ has been shown to have good reliability and validity (McCracken et al., 2004). In this study, Cronbach's $\alpha$ was $\alpha=.76$.

\subsection{Statistical strategy}

In line with the recommendations of Gerbing and Hamilton (1996) we used a two-step strategy to investigate the construct validity of the PaSol. Using Monte Carlo methods, Gerbing and Hamilton (1996) found that Exploratory Factor Analysis (EFA) contributes to model specification prior to cross-validation using Confirmatory Factor Analysis (CFA). In this strategy, EFA is considered "a useful tool to aid the researcher in recovering an underlying measurement model that can then be evaluated with CFA" (p. 71).

In a first step, EFA was conducted on the entire sample. Principal axis factoring and orthogonal varimax rotation was used to identify the underlying model. The scree test (Cattell, 1978 ) with the criterion of an eigenvalue $>1$ was used to determine the number of factors. Using the criteria provided by Comrey and Lee (1992) only factor loadings higher than .32 were interpreted.

In the second step, the sample was randomly split into two subsamples, a calibration sample $\left(n_{1}=238\right)$ and a validation sample $\left(n_{2}=238\right)$. Data of the calibration sample were used to explore the identified model with CFA (AMOS 5; Arbuckle, 2003). A model was built that met the goodness-of-fit criteria. The validation sample was used to cross-validate the solution. The fit of the model was estimated with the Maximum Likelihood algorithm while allowing the latent variables to correlate. Each item was assumed to load only on one factor. In line with the recommendations of Bollen and Long (1993) and Byrne (2001), model fit was assessed using several fit indices, amongst which were $\chi^{2}$ divided by the degrees of freedom (CMIN/DF), root mean square error of approximation (RMSEA), goodness-of-fit index (GFI), adjusted goodness-of-fit index (AGFI) and comparative fit index (CFI).

Finally, we investigated the reliability and validity of the PaSol. The internal consistency was calculated. The construct validity was explored by correlating the PaSol subscales to subscales assessing related constructs. The criterion validity of the PaSoL was investigated by correlating the PaSol subscales to measures of affective distress and disability, and to process-related variables (e.g., vigilance and pain catastrophizing). Finally the unique contribution of the PaSol subscales in accounting for variability in affective distress and disability was tested using hierarchical multiple regression analyses.

\section{Results}

\subsection{Exploratory factor analysis}

An EFA revealed a 5-factor solution. However, both items that loaded on the fifth factor had a stronger loading on the first factor. Therefore, this fifth factor was omitted. This solution accounted for $45.58 \%$ of the variance. Inspection of the factor loadings (see Table 1) showed that item 2 had no significant loading on any of the four factors. Item 6 had a low loading on the second factor. These two items were excluded from further analyses. The remaining 21 items loaded substantially on at least one of the four factors.

Factor I was labelled 'solving pain'. Eight items captured the approach to the problem of pain as a

Table 1

The factor loadings of the 5 -factor solution

\begin{tabular}{|c|c|c|c|c|c|c|}
\hline \multicolumn{2}{|l|}{ Items } & \multicolumn{5}{|c|}{ Factor } \\
\hline Tested version & Final version & I & II & III & IV & $\mathrm{V}$ \\
\hline 1 & 1 & & .68 & & & \\
\hline 2 & & & & & & \\
\hline 3 & & .47 & .42 & & & \\
\hline 4 & 2 & & .72 & & & \\
\hline 5 & 3 & & .48 & .35 & & \\
\hline 6 & & & & & & \\
\hline 7 & 4 & & & .73 & & \\
\hline 8 & & & & .41 & & \\
\hline 9 & 5 & & & .64 & & \\
\hline 10 & & & & .42 & & \\
\hline 11 & & & .49 & & & \\
\hline 12 & 6 & & & & .69 & \\
\hline 13 & 7 & .71 & & & & \\
\hline 14 & 8 & & .61 & & & \\
\hline 15 & & .43 & & & & .38 \\
\hline 16 & 9 & & & .71 & & \\
\hline 17 & 10 & .80 & & & & \\
\hline 18 & & .53 & -.40 & & & .42 \\
\hline 19 & 11 & .81 & & & & \\
\hline 20 & 12 & .65 & & & & \\
\hline 21 & & .39 & & & & \\
\hline 22 & 13 & & .65 & & & \\
\hline 23 & 14 & & & & .84 & \\
\hline
\end{tabular}

Only factor loadings larger than .32 are displayed. 
persistence in active strategies to solve the pain (e.g., "I keep searching for ways to control my pain"). Factor II was labelled 'meaningfulness of life despite pain'. Six items captured the approach to the problem of pain as the attempt to find meaning beyond or despite pain (e.g., "Even when I am in great pain, I find my life still meaningful"). Factor III was labelled 'acceptance of the insolubility of pain'. Five items captured an approach to the problem of pain as an ability to disengage from problem-solving attempts and to accept the uncontrollability of their pain (e.g., "I can accept that I cannot control my pain"). Factor IV consisted of two items, and was labelled 'belief in a solution'. We judged both items to capture a belief that an external solution would be discovered to the problem of pain ("I have confidence that they will find a solution for my pain" and "I am convinced that there is a treatment for my pain").

\subsection{Confirmatory factor analysis}

The 4-factor structure was tested with CFA using the calibration sample. The items 3, 8, 10, 11, 15, 18 and 21 were removed from the model. Because of their low factor loadings on the factor structure, they lowered the fitindices when entered in the CFA individually or in all the possible combinations (fit-indices for the untested version were $\chi^{2}(\mathrm{df})=884.637 \quad(183) ; \mathrm{CMIN} / \mathrm{DF}=$ 4.83; $\quad$ RMSEA $=.095 ; \quad$ GFI $=.821 ; \quad$ AGFI $=.774$ ). These items were omitted from further analyses. This reduced the item set from 21 to 14 . Appendix B contains the English translation of the final version. Factor I (Solving Pain) had four items (13-17-19-20), factor II (Meaningfulness of Life Despite Pain) had five items (1-4-5-14-22), factor III (Acceptance of the Insolubility of Pain) had three items (7-9-16), and factor IV (Belief in a Solution) had two items (12-23).

After inspection of the Modification Indices, a correlated residual between items 1 and 4 was detected. This residual is probably due to a content overlap between the items. The 4-factor model was refitted to the data, allowing a free estimation of the error covariance between items 1 and 4 . This change resulted in a significant improvement of the model fit. Inspection of the modificated indices indicated that other minor improvements were possible, but it was decided not to include these changes because of model parsimony.
Using the validation sample the construct validity of the final model was cross-validated. Table 2 presents the goodness-of-fit indices for the final 4-factor solution for the calibration and the validation sample. Indices indicate a reasonable fit for the 4 -factor model. Fig. 1 displays the standardized factor loadings of the 4-factor model for the calibration sample and the validation sample.

\subsection{Internal consistency and validity}

Table 3 summarizes the descriptive statistics, the internal consistency (Cronbach's $\alpha$ ) and Pearson intercorrelations for each PaSol subscale for the entire sample. Cronbach's $\alpha$ coefficients varied from .78 to .86, indicating that the subscales are internally consistent. The intercorrelations were moderate. The Solving Pain subscale was negatively related to the Acceptance of the Insolubility of Pain subscale, and positively to the Belief in a Solution scale. The Meaningfulness of Life Despite Pain subscale was positively related to Acceptance of the Insolubility of Pain subscale and the Belief in a Solution subscale.

The construct and criterion validity was investigated using Pearson correlations. These correlations are also presented in Table 3. We expected the PaSol subscales to be correlated with the subscales of the acceptance measure (CPAQ). As expected, the Meaningfulness of Life Despite Pain subscale (PaSol) was moderately and positively related to the Engagement subscale of the CPAQ (assessing a pursuit of life activities regardless of pain). To our surprise, the Acceptance of the Insolubility of Pain subscale (PaSol) was not significantly related to the Pain Willingness subscale of the CPAQ (assessing a recognition that avoidance and control are not effective in adapting to chronic pain). It was the Solving Pain subscale (PaSol) that was negatively related to the Pain Willingness subscale. In an attempt to reconcile this unexpected finding, we analyzed the item content of the Pain Willingness subscale (CPAQ). This analysis revealed that almost all items (6 out of 9, e.g., "I need to concentrate on getting rid of my pain") of that subscale were related to attempting to avoid or to control pain instead of to the explicit recognition that attempts to avoid or control pain are ineffective.

Table 2

Goodness-of-fit indices of the 4-factor PaSol solution for the calibration sample $\left(n_{1}=238\right)$ and the validation sample $\left(n_{2}=238\right)$

\begin{tabular}{lllllll}
\hline & $\chi^{2}(\mathrm{df})$ & CMIN/DF & RMSEA & GFI & AGFI & CFI \\
\hline Calibration sample & $139.04(70)$ & 1.99 & 0.068 & 0.92 & 0.88 \\
Validation sample & $158.04(70)$ & 2.26 & 0.077 & 0.90 & 0.96 & 0.93 \\
\hline
\end{tabular}

CMIN/DF, $\chi^{2}$ divided by the degrees of freedom; RMSEA, root mean square error of approximation; GFI, goodness-of-fit index; AGFI, adjusted goodness-of-fit index; CFI, comparative fit index. 


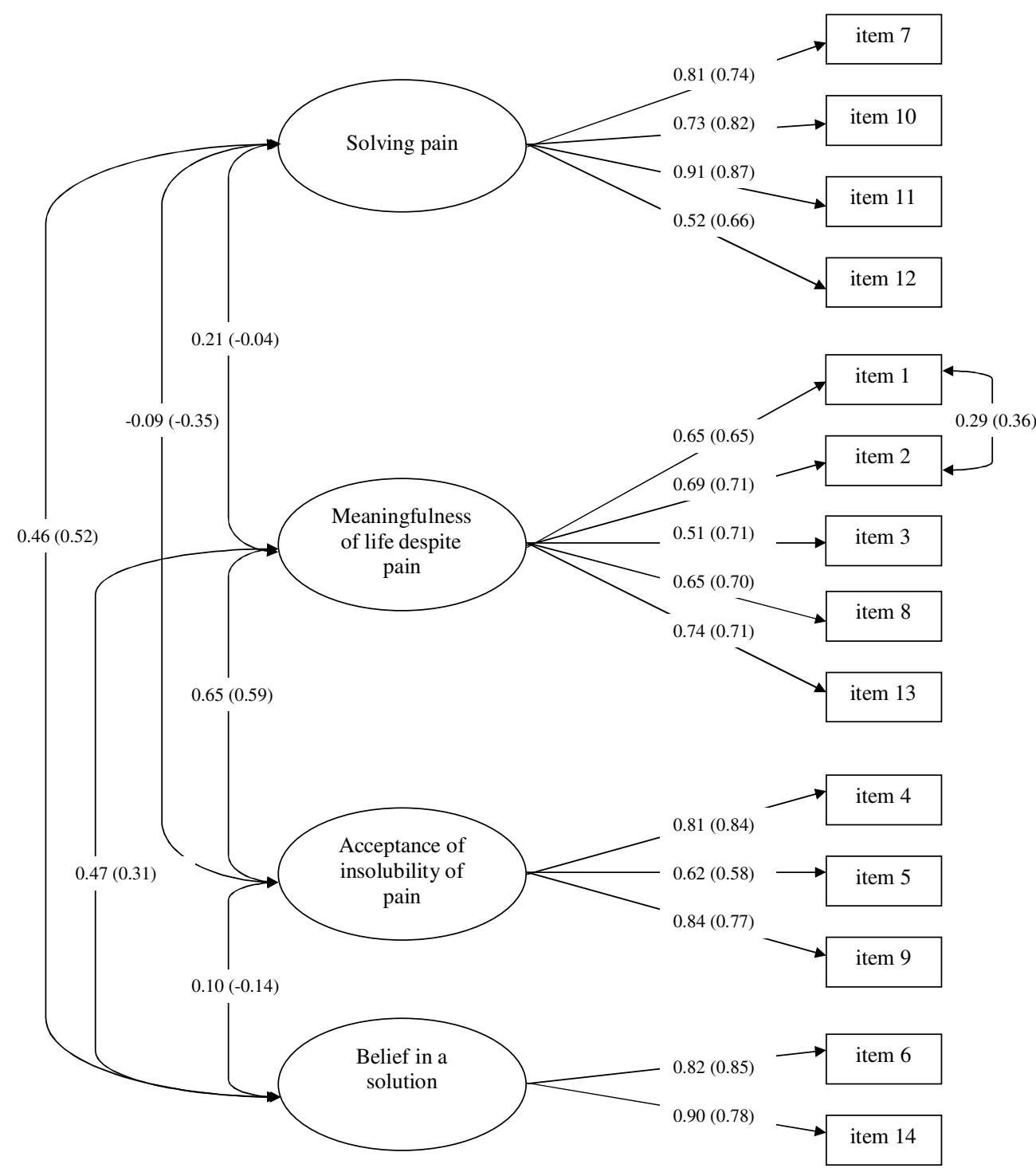

Fig. 1. Standardized factor loadings of the 4-factor model as obtained with confirmatory factor analysis shown for the calibration sample and the validation sample (between parentheses). Numbering from the final version is used here.

A differential pattern emerged between the PaSol subscales and several outcome variables. Most correlations between the PaSol and the outcome measures were significant. For narrative reasons we focus upon correlations larger than .25. The Solving Pain subscale was positively related to attention to pain (PVAQ) and catastrophic thinking (PCS). The Meaningfulness of Life Despite Pain subscale was negatively related to attention to pain (PVAQ), catastrophic thinking about pain (PCS), distress (HADS) and pain-related disability (PDI). The Acceptance of the Insolubility of Pain subscale was negatively related to catastrophic thinking (PCS) and distress (HADS). The Belief in a Solution subscale had no moderate relations with any outcome measure.

In a further investigation of the criterion validity, multiple hierarchical regression analyses were performed to investigate the unique value of the PaSol subscales in explaining distress (HADS) and pain-related disability (PDI). In these regression analyses age and gender (male $=0$, female $=1$ ) were entered in a first block to control for demographic variables. Next, pain duration and pain severity were entered to control for pain characteristics. Data for pain duration were $\log 10$ transformed, because the assumption of normality was not met. The subscales of the PaSol were entered in a third block. Table 4 summarizes the results of these analyses. The analysis with pain-related disability as a dependent variable revealed that the Meaningfulness of Life Despite Pain subscale was related to less pain-related disability, even after controlling for the effects of demographic and pain characteristics. The analysis with affective distress as a dependent variable revealed that the Meaningfulness of Life Despite Pain subscale was 


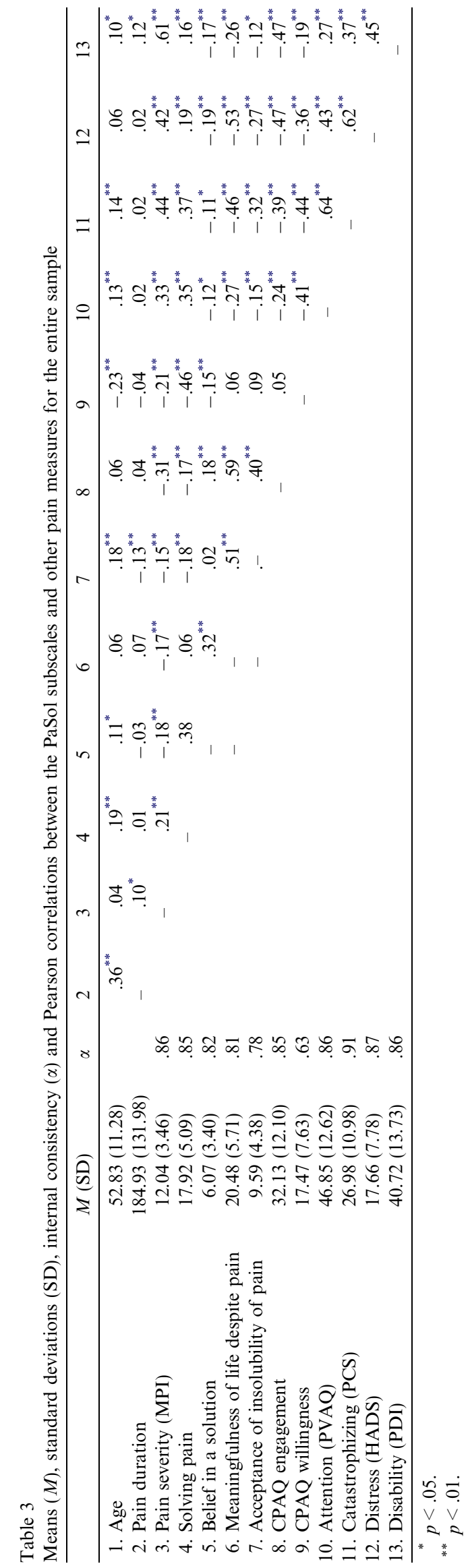

associated with less affective distress, and that the Solving Pain subscale was associated with more affective distress. The latter effects were significant, even after controlling for demographic and pain characteristics.

\section{Discussion}

This study reports the development of a questionnaire, labelled the Pain Solutions Questionnaire (PaSol) that was designed to assess different attitudes to solving the problem of pain. Exploratory and confirmatory factor analyses resulted in a 14-item instrument with an adequate oblique 4-factor structure: (1) Solving Pain scale (4 items), (2) Meaningfulness of Life Despite Pain scale (5 items), (3) Acceptance of the Insolubility of Pain scale (3 items), and (4) Belief in a Solution scale (2 items). The validity of the PaSol was further tested by its value in explaining disability and affective distress after controlling for the effects of the demographic characteristics and pain severity. The Meaningfulness of Life Despite Pain scale was important in accounting for the variability of disability and affective distress. The Solving Pain scale had a unique and independent contribution in explaining affective distress. Construct validity was further confirmed by its interrelationships with the subscales of the Chronic Pain Acceptance Questionnaire (McCracken et al., 2004).

The PaSol was developed following the dual process model of coping, introduced by Brandtstädter and Renner (1990) that identifies two opposing modes of coping. Assimilative coping involves attempts to meet the blocked or unmet goal by directing efforts at changing the situation or obstacle. Accommodative coping involves a resolution of the problem by changing the goal or the importance of the goal to be met. Assimilative coping within the PaSol is captured by the Solving Pain scale. Those scoring high on this scale persist in attempting to cure or control pain. Accommodative coping with pain is captured by the Acceptance of the Insolubility of Pain scale and the Meaningfulness of Life Despite Pain scale.

The PaSol is distinctive as a measure of coping with pain insofar as it is developed from an action-oriented and goal-dependent theory of how people construct problems and seek solutions. Traditional approaches to coping are often based upon cross-behavioural, context-free, structural similarities such as active versus passive, problem-focused versus emotion-focused, or cognitive versus behavioural strategies. Skinner et al. (2003) recently argued that these classification systems are inadequate and insufficient when applied in specific health domains, often failing to capture the function of behaviour in context. The adaptive value of action is context dependent. What is important for the success of a coping strategy is the match between the appraisal 
Table 4

Summary of the hierarchical multiple regression analyses with pain-related disability (PDI) and affective distress (HADS) as dependent variables. In each regression analysis, gender, age, pain duration, pain severity and the PaSol-subscales were entered as independent variables

\begin{tabular}{|c|c|c|c|c|c|}
\hline Criterium variable & Block & Predictor & $\beta$ & $\Delta R^{2}$ & Adjusted $R^{2}$ \\
\hline \multirow[t]{3}{*}{ 1. Disability (PDI) } & 1 & $\begin{array}{l}\text { Age } \\
\text { Gender }\end{array}$ & $\begin{array}{r}.08 \\
-.04\end{array}$ & $.02^{*}$ & .01 \\
\hline & 2 & $\begin{array}{l}\text { Pain duration } \\
\text { Pain severity }\end{array}$ & .03 & $.37^{* * *}$ & .38 \\
\hline & 3 & $\begin{array}{l}\text { Solving pain } \\
\text { Meaningfulness } \\
\text { Acceptance } \\
\text { Belief }\end{array}$ & $\begin{array}{l}.05 \\
-.17^{* * *} \\
.03 \\
-.03\end{array}$ & $.03^{* * *}$ & .41 \\
\hline \multirow[t]{3}{*}{ 2. Distress (HADS) } & 1 & $\begin{array}{l}\text { Age } \\
\text { Gender }\end{array}$ & $\begin{array}{c}.05 \\
-.09^{*}\end{array}$ & .01 & .01 \\
\hline & 2 & $\begin{array}{l}\text { Pain duration } \\
\text { Pain severity }\end{array}$ & $\begin{array}{l}.05 \\
.29^{* * * *}\end{array}$ & $.17^{* * *}$ & .18 \\
\hline & 3 & $\begin{array}{l}\text { Solving pain } \\
\text { Meaningfulness } \\
\text { Acceptance } \\
\text { Belief }\end{array}$ & $\begin{array}{l}.18^{* * *} \\
-.50^{* * *} \\
.03 \\
-.02\end{array}$ & $.24^{* * *}$ & .41 \\
\hline
\end{tabular}

$\begin{aligned}{ }^{*} p & <.05 \\ & p<.005 .\end{aligned}$

of the problem and its solution. For example, the tenacious and unswerving pursuit of a cure for pain may well be appropriate if and when pain is curable. However, such a rigid pursuit of a cure as the only solution to the problems brought about by pain may be ineffective and bring further problems if and when the pain is persistent and incurable.

In this self-help sample of people with chronic pain there is evidence that an assimilative coping style aimed at solving the problem of pain may have cognitive and affective consequences. The pursuit of cure and analgesia was related to a heightened attention to pain. Accepting that pain is insoluble and believing that life is meaningful despite pain were both related to less attention to pain. It may be that a corollary of attempting to solve pain is the repeated selection of the goal of pain relief at the expense of other goals (Rothermund, in press), inadvertently promoting a hypervigilance to pain (Viane et al., 2004; Crombez et al., 2005). Similarly, attempting to solve uncontrollable pain was associated with affective distress contributing independently beyond pain severity. Repeatedly attempting and failing to solve chronic pain may fuel feelings of frustration and promote a stable distress (Aldrich et al., 2000).

Constructing pain as a problem that needs to be directly solved, failing to accept that pain is insoluble, and not believing in the possibility of a meaningful life whilst in pain were all associated with catastrophic thinking about pain and its negative consequences. Catastrophic thinking is here associated with an assimilative style of coping, as assessed with the PaSol. It is notewor- thy that those who catastrophize about pain seem to persist in their attempts to find a solution for their pain, despite a low belief that a solution is possible. Further research is necessary to better understand the relationship between catastrophic thinking about pain and assimilative coping.

There are at least three avenues of research that could be followed. First, there is as yet no evidence for the idea that an assimilative style of coping is implicated in the development of pain-related disability and distress. Second, there is no evidence for the idea that for chronic pain patients catastrophizing about pain is the distressing consequence of persistent and repetitive attempts to solve an insoluble problem. We know of no experimental or prospective data to help. Third, there is no evidence that chronic pain patients have a deficit in general problem solving skills (De Vlieger et al., 2006). Instead, what may be important is the 'rigidity' or 'fixedness' of the solution once formulated. Future research might investigate whether chronic pain patients are less flexible in disengaging from the goal to find analgesia, and, if so, how this goal becomes so fixed as the only solution to the problems of chronic pain, often in spite of repeated exposure to disconfirmatory evidence.

There are some limitations to this study. First, we intend the PaSol to be used in all situations in which pain can be constructed as part of a problem in need of a solution. However, we have only explored its psychometric properties with a self-defined chronic pain population, which may not be a representative sample of pain patients. Therefore, one should be mindful 
when using the descriptive statistics as normative data. Further study is needed with different populations of both acute and chronic pain patients. Second, our findings are based on a cross-sectional design. Third, this study relied upon self-report. Of interest in the future may be the relationship between attitudes to problem solving in pain and actual attempts at problem solving.

\section{Acknowledgements}

We want to thank the following pain experts who provided feedback about the item set: Johan Vlaeyen, Madelon Peters, Andrea Evers and Ilse Viane. We also want to thank the Flemish Pain League who coordinates several self-help groups for pain patients in Belgium for their cooperation.

\section{Appendix A.}

PaSol - untested English version

1. Even when I have severe pain, I still find my life meaningful.

2. To avoid disappointments, I don't set my expectations about treatment too high.

3. I keep fighting against my pain.

4. Even when I have severe pain I can see a way out.

5. I try to live with my pain.

6. I don't hold on to the idea that my pain will last forever.

7. I can live with the idea that there is no solution for my pain

8. I know that it is not always meaningful to try to solve my pain.

9. I can accept that I can't control my pain.

10. I quit trying to solve my pain.

11. At present, there are other things more important than my pain.

12. I have confidence that they will find a solution for my pain.

13. I keep searching for ways to control my pain.

14. I try to make the best of my life, despite the pain.

15. I will only be completely happy when I no longer have pain.

16. I can accept that there is no solution for my pain.

17. I try everything to get rid of my pain.

18. I will not find peace as long as I am in pain.

19. I keep searching for a solution for my pain.

20. I would do anything to be without pain.

21. Because of the pain, I don't make great plans for the future.

22. I don't let the pain get in my way.

23. I am convinced that there is a treatment for my pain.

\section{Appendix B.}

The Possible Solutions to Pain Questionnaire (PaSol) - English version

People who have pain develop different ways to respond to that pain. We would like to know how you deal with the problem of pain. Please read each statement and indicate the extent to which the following thoughts or activities apply for you now. Please mark your response by circling the number to the right of each statement from 0 (not at all applicable) to 6 (highly applicable)

\begin{tabular}{|c|c|c|c|c|c|c|c|}
\hline & $\begin{array}{l}0 \\
\text { Not at all } \\
\text { applicable }\end{array}$ & 1 & 2 & 3 & \multicolumn{3}{|c|}{$\begin{array}{l}\text { Highly } \\
\text { applicable }\end{array}$} \\
\hline 1. Even when I have severe pain, I still find my life meaningful. & 0 & 1 & 2 & 3 & 4 & 5 & \\
\hline 2. Even when I have severe pain, I can see a way out. & 0 & 1 & 2 & 3 & 4 & 5 & \\
\hline 3. I try to live with my pain. & 0 & 1 & 2 & 3 & 4 & 5 & \\
\hline 4. I can live with the idea that there is no solution for my pain. & 0 & 1 & 2 & 3 & 4 & 5 & \\
\hline 5. I can accept that I can't control my pain. & 0 & 1 & 2 & 3 & 4 & 5 & \\
\hline
\end{tabular}




\begin{tabular}{|c|c|c|c|c|c|c|c|}
\hline & $\begin{array}{l}0 \\
\text { Not at all } \\
\text { applicable }\end{array}$ & 1 & 2 & 3 & & $\begin{array}{l}5 \\
\text { ly } \\
\text { cal }\end{array}$ & 6 \\
\hline 6. I have confidence that they will find a solution for my pain. & 0 & 1 & 2 & 3 & 4 & 5 & 6 \\
\hline 7. I keep searching for ways to control my pain. & 0 & 1 & 2 & 3 & 4 & 5 & 6 \\
\hline 8. I try to make the best of my life, despite the pain. & 0 & 1 & 2 & 3 & 4 & 5 & 6 \\
\hline 9. I can accept that there is no solution for my pain. & 0 & 1 & 2 & 3 & 4 & 5 & 6 \\
\hline 10. I try everything to get rid of my pain. & 0 & 1 & 2 & 3 & 4 & 5 & 6 \\
\hline 11. I keep searching for a solution for my pain. & 0 & 1 & 2 & 3 & 4 & 5 & 6 \\
\hline 12. I would do anything to be without pain. & 0 & 1 & 2 & 3 & 4 & 5 & 6 \\
\hline 13. I don't let the pain get in my way. & 0 & 1 & 2 & 3 & 4 & 5 & 6 \\
\hline 14. I am convinced that there is a treatment for my pain. & 0 & 1 & 2 & 3 & 4 & 5 & 6 \\
\hline
\end{tabular}

Scoring

- Solving Pain: sum score of items 7, 10, 11 and 12.

- Meaningfulness of Life Despite Pain: sum score of items 1, 2, 3, 8 and 13.

- Acceptance of the Insolubility of Pain: sum score of items 4, 5 and 9.

- Belief in a Solution: sum score of items 6 and 14.

\section{References}

Aldrich S, Eccleston C, Crombez G. Worrying about chronic pain: vigilance to threat and misdirected problem solving. Behav Res Ther 2000;38:457-70.

Arbuckle JL. Amos 5.0 update to the Amos user's guide. Chicago, IL: SPSS; 2003.

Bollen KA, Long JS. Testing structural equation models. Newbury Park (CA): Sage; 1993.

Brandtstädter J, Renner G. Tenacious goal persuit and flexible goal adjustment: explication and age-related analysis of assimilative and accommodative strategies of coping. Psychol Aging 1990;5:58-67.

Byrne BM. Structural equation modeling with Amos: basic concepts, applications and programming. New Jersey (NJ): Lawrence Erlbaum Associates, Inc; 2001.

Cattell RB. The scientific use of factor analysis in behavioural and life sciences. New York (NY): Plenum press; 1978.

Comrey AL, Lee HB. A first course in factor analysis. 2nd ed. Hillsdale, NJ: Erlbaum; 1992.

Crombez G, Van Damme S, Eccleston C. Hypervigilance to pain: an experimental and clinical analysis. Pain 2005;116:4-7.

Crombez G, Vlaeyen JWS, Van Houdenhove B, Wauters K. 1999. The chronic pain acceptance questionnaire (CPAQ): authorized Dutch translation.

De Vlieger P, Crombez G, Eccleston C. Worrying about chronic pain. An examination of worry and problem solving in adults who identify as chronic pain sufferers. Pain 2006;120:138-44.

Evers AWM, Kraaimaat FW, van Lankveld W, Jongen PJH, Jacobs JWG, Bijlsma WJ. Beyond unfavorable thinking: the illness cognition questionnaire for chronic diseases. J Consult Clin Psychol 2001;69:1026-36.

Hinkle DE, Oliver JD, Hinkle CA. How large should the sample be.2. The one-sample case for survey-research. Educ Psychol Meas 1985;45:271-80.

Gerbing DW, Hamilton JG. Variability of exploratory factor analysis as a precursor to confirmatory factor analysis. Struct Equation Model 1996;3:62-72.

Keefe FJ, Rumble ME, Scipio CD, Giordano LA, Perri LM. Psychological aspects of persistent pain: current state of the science. J Pain 2004;5:195-211.
Linton SJ. Occupational psychological factors increase the risk for back pain: a systematic review. J Occup Rehabil 2001;11:53-66.

Lousberg R, Van Breukelen GJP, Groenman NH, Schmidt AJM, Arntz A, Winter FAM. Psychometric properties of the Multidimensional Pain Inventory, Dutch language version (MPI-DLV). Behav Res Ther 1999;37:167-82.

McCracken LM. Attention to pain in persons with chronic pain: a behavioural approach. Behav Ther 1997;28:271-84.

McCracken LM, Vowles KE, Eccleston C. Acceptance of chronic pain: component analysis and a revised assessment method. Pain 2004;107:159-66.

Pollard CA. Preliminary validity of the Pain Disability Index. Percept Mot Skills 1984;59:974.

Roelofs J, Peters ML, McCracken L, Vlaeyen JWS. The pain vigilance and awareness questionnaire (PVAQ): further psychometric evaluation in fibromyalgia and other chronic pain syndromes. Pain 2003;101:299-306.

Rothermund K. Hanging on and letting go in the pursuit of health goals: psychological mechanism to cope with a regulatory dilemma. In: De Ridder D, De Wit J, editors. Self-regulation in health behaviour, Chichester: John Wiley and Sons Ltd. [in press].

Schmitz U, Saile H, Nilges P. Coping with chronic pain: flexible goal adjustment as an interactive buffer against pain-related distress. Pain 1996;67:41-51.

Skinner EA, Edge K, Altman J, Sherwood H. Searching for the structure of coping: a review and critique of category systems for classifying ways of coping. Psychol Bull 2003;129:216-69.

Spinhoven P, Ormel J, Sloekers PPA, Kempen GIJM, Speckens AEM, Van Hemert AM. A validation study of the Hospital Anxiety and Depression Scale (HADS) in different groups of Dutch subjects. Psychol Med 1997;27:363-70.

Tait RC, Chibnall JT, Krause S. The Pain Disability Index: psychometric properties. Pain 1990;40:171-82.

Viane I, Crombez G, Eccleston C, Poppe C, Devulder J, Van Houdenhove B, et al. Acceptance of pain is an independent predictor of mental well-being in patients with chronic pain: empirical evidence and reappraisal. Pain 2003;106:65-72.

Viane I, Crombez G, Eccleston C, Devulder J, De Corte W. Acceptance of the unpleasant reality of chronic pain: effects upon attention to pain and engagement with daily activities. Pain 2004;112:282-8. 